\title{
Functionalization of immunostimulating complexes (ISCOMs) with lipid vinyl sulfones and their application in immunological techniques and therapy
}

\author{
This article was published in the following Dove Press journal: \\ International Journal of Nanomedicine \\ 30 November 2012 \\ Number of times this article has been viewed
}

\author{
Teresa Cruz-Bustos ${ }^{1, *}$ \\ Gloria González- \\ González1,* \\ Julia Morales-Sanfrutos ${ }^{2}$ \\ Alicia Megía-Fernández ${ }^{2}$ \\ Francisco Santoyo- \\ González ${ }^{2}$ \\ Antonio Osuna' \\ 'Molecular Biochemistry and \\ Parasitology Research Group, \\ Department of Parasitology, Institute \\ of Biotechnology, Faculty of Sciences, \\ University of Granada, Granada, Spain; \\ ${ }^{2}$ Department of Organic Chemistry, \\ Institute of Biotechnology, Faculty \\ of Sciences, University of Granada, \\ Granada, Spain \\ *These authors contributed equally \\ to this work
}

\begin{abstract}
Background: Immunostimulating complexes (ISCOM)-type nanocapsules have been functionalized with lipid vinyl sulfones that anchor to them via the hydrophobic zone of their structure and can be charged with pharmacologically active molecules or macromolecules. These functionalized nanocapsules can incorporate protein $\mathrm{A}$ and bind to $\mathrm{G}$ immunoglobulins (IgGs) to make vehicles directed at the surface antigens of infectious agents, tumor cells, or receptor cells and deliver the encapsulated molecules in a highly specific way. They may be of particular use in pharmacological treatments with highly toxic molecules that should not be used in solution whenever it can be avoided. When bound to antibodies they can be used in biological processes that require the delivery or presentation of macromolecules to certain specific cells, in immunization processes for instance, or in diagnostic immunological techniques, as they are able to transport both the secondary antibodies and the reaction labels.
\end{abstract}

Methods and results: We describe the preparation of ISCOMs, the binding to the ISCOMS of newly synthesized compounds composed of chain alkyl vinyl sulfone, and the subsequent binding of the vinyl-sulfone compounds to IgGs. Within this context, a compound deriving from cholesterol functionalized with vinyl sulfone and used together with cholesterol in varying proportions has been linked to the structure of the ISCOMs and bound to protein A-IgG. This functionalization in no way altered the form or structure of the ISCOMs and allowed the nanocapsules carrying the specific IgGs to bind to forms of Trypanosoma cruzi against which antibodies had been developed. The fact that functionalized ISCOMs containing antibodies could deliver actinomycin $\mathrm{D}$ directly to the parasite meant that the effective dose of the antibiotic could be reduced very significantly.

Conclusion: We have developed ISCOM-type nanocapsules functionalized with lipid vinyl sulfone capable of anchoring to the surface of functional IgGs, which favors the recognition and transport of these nanocapsules precisely to certain kinds of cell.

Keywords: nanoparticle, protein A, actinomycin D, IgG, Trypanosoma cruzi, vinyl sulfone

\section{Introduction}

The development of nanotechnology applied to biomedicine has undergone extraordinary advances since Gregoriadis, ${ }^{1,2}$ Gregoriadis and Neerunjun, ${ }^{3}$ and Segal et $\mathrm{al}^{4}$ developed liposomes, which are nanocapsules composed of an external lipid bilayer made up of phospholipids and cholesterol. Since then liposomes have been used as delivery systems both for drugs and for targeted immunization purposes. ${ }^{5}$ Hydrophobic molecules are inserted into their lipid bilayer whilst hydrophilic ones are confined to the inner aqueous part of the nanocapsule. In this way liposomes are
Correspondence: Antonio Osuna Bioquímica y Parasitología Molecular, Edificio Mecenas, Campus Universitario de Fuentenueva, 1807I, Granada, Spain Tel +34958244 I63

Fax +34958243174

Email aosuna@ugr.es 
capable of encapsulating and conveying macromolecules or drugs, thus allowing greater bioavailability and diminishing their possible toxicity and side-effects. The specificity of the delivery can also be increased by modifying the surface of the nanocapsule in question with antibodies or ligands in order to allow it to bind to target molecules in body tissues or cells. ${ }^{6,7}$

In 1975, Gregoriadis, ${ }^{1,2}$ Gregoriadis and Neerunjun, ${ }^{3}$ and Segal et $\mathrm{al}^{4}$ pointed the way to some of the possible applications for liposomes when they published the results of their studies of liposomes' transport capacity to tumors and even their potential use in the treatment of metabolic disorders. Since then, many types of nanocapsules have been designed, some made of lipids and some composed of various polymers or even metals, but all developed for use as carriers to transport drugs or immunization agents more efficiently to the immune system.

The problem with using liposomes resides in their innate instability due to their physico-chemical properties and lack of immunogenicity. To avoid these drawbacks, cholesterol can be included in their make-up to afford greater stability to the bilayer, together with adjuvants to increase their immunogenicity. ${ }^{8}$ Among these latter, one of the most commonly used is the Quillaja saponin, which, depending on its concentration, ${ }^{9}$ forms pentagonal dodecahedral balls of uniform size (40 nm), much like soccer balls, ${ }^{10,11}$ known as immunostimulating complexes (ISCOMs). ${ }^{12}$ These nanostructures were first seen to appear when treating viral particles with saponin and also when they were created with artificial membranes of phosphatidylcholine-cholesterol and the Quillaja saponin Quil A. They were originally designed as immunostimulating systems for vaccination purposes, ${ }^{11}$ and are known either as ISCOMs or ISCOM matrices (ISCOMs with no incorporated antigen); these latter are similar in size and shape to the former and have a strong negative charge. ${ }^{9}$ Several reviews of ISCOMs have been published recently, ${ }^{5-7}$ reporting on their uses as adjuvants for vaccines, carrying the antigens for systemic, oral and intranasal administration, ${ }^{13,14}$ and as delivery systems for DNA vaccines. ${ }^{15}$ They have also been used as carriers of antigens in immunoenzyme assays, in which the antigen is encapsulated in such a way as to be recognized by the immunoglobulins present in the blood or other biological fluids such as milk. ${ }^{8,9,11,16-18}$

The basis of the unique structure of ISCOMs and ISCOM-matrices is the interaction between the saponin and cholesterol molecules, which, when combined, form stable rings in aqueous solutions after the removal of detergents. The immunogenic activity of the saponin depends on the aldehyde groups, which are capable of forming Schiff bases with the amino groups of the proteins. ${ }^{19}$ The rings are held together by hydrophobic interactions, steric factors, and possibly hydrogen bonds. ${ }^{20}$ Phospholipid (typically egg-derived phosphatidylcholine ${ }^{10}$ or phosphatidylethanolamine $)^{21}$ is needed when protein is to be incorporated into an ISCOM structure. It has been suggested that this promotes a less rigid structure than saponin and cholesterol alone and thus allows bulky amphipathic molecules such as viral membrane proteins to be inserted into the ISCOM structure. ${ }^{10}$

A major limitation of ISCOM technology is that most soluble proteins do not usually contain exposed hydrophobic regions and are therefore difficult to incorporate into the ISCOM structure. Although it is possible to insert nonamphipathic molecules into ISCOMs, or at least associate them, structural modifications such as the partial denaturation of proteins are required to expose normally internal hydrophobic regions within proteins, ${ }^{22,23}$ but these methods may lead to a loss of conformationally dependent B-cell epitopes. ${ }^{22,23}$ An alternative strategy is to attach fatty acids covalently to soluble proteins. The bioconjugation of such molecules is normally achieved chemically through the use of acid chlorides or activated ester derivatives of these fatty acids. By using this chemical strategy, a number of soluble proteins, including ovalbumin (OVA), cytochrome C, Tamm Horsfall glycoprotein, and HIV-1 gp120, have been successfully incorporated into ISCOMs after attaching palmitic acid via the $\varepsilon$-amine groups of lysine. ${ }^{24}$ Mowat et a ${ }^{25}$ found that palmitified OVA could be incorporated into ISCOMs and that this formulation was capable of inducing delayedtype hypersensitivity (DTH) responses in mice when it was injected into the footpad. Palmitified ${ }^{26}$ OVA or palmitified OVA mixed with Quil A or an ISCOM matrix, on the other hand, induced no such DTH effect. It should be noted, however, that this fatty acylation strategy offers considerable drawbacks as the acid chlorides and activated ester derivatives of such molecules are normally not very soluble in water and are also sensitive to this solvent, to the extent that they easily undergo hydrolysis in this reaction medium.

In the arsenal of bioconjugation methods available, although less commonly used, vinyl-sulfone chemistry constitutes a straightforward, efficient strategy for the covalent coupling of different tags to biomolecules. ${ }^{26-29}$ This ligation tool takes advantage of the excellent reactivity of vinyl sulfones via Michael-type addition with the amine- or thiolbearing residues naturally occurring on the side chains of proteins under mild conditions that preserve the functionality and biological integrity of the biomolecule. In this way 
the appealing features of this reaction can be useful for the covalent grafting of protein A to ISCOMs without disrupting their ability to bind immunoglobulins.

We describe here a process developed in our laboratory by which we are able to incorporate soluble proteins into ISCOMs through the covalent attachment of a hydrophobic chain via vinyl sulfone, which will allow this type of functionalized nanocapsule to be used both in immunological techniques and in therapy against pathogens or tumors by carrying antigenic molecules specifically to cells presenting antigens, or iRNA to cells in which we want to silence a gene.

\section{Materials and methods}

Phycocyanin was obtained from spirulina as described in the literature. ${ }^{30}$ Actinomicyn D, cholesterol (C), phosphatidylcholine (PC), decanoyl-N-methyl-glucamide (MEGA-10), protein $\mathrm{A}$, acetic acid, methanol, acetonitrile, phenylenediamine dihydrochloride, goat anti-mouse Fab conjugated with horseradish peroxidase (HRP), polyoxyethylensorbitan monolaurate (Tween 20), formaldehyde, glutaraldehyde, Bradford reagent, Freund's complete adjuvant, Freund's incomplete adjuvant, EDTA, sucrose, $\mathrm{KCl}$, dithiothreitol (DTT), and Triton X-100 were all bought from Sigma-Aldrich (St Louis, MO). The Quillaja saponin was a gift from Prof A Martinez (Faculty of Pharmacy, Univ Complutense, Madrid). The protease inhibitors antipain-hydrochloride, bestatin, cimostatin, E-64, leupeptin, pepstatin, phosphoramidon, pefabloc SC, and aprotinin were bought from Roche Diagnostics (GmbH, Manheim, Germany). The protein A sepharose column was from GE (GE Healthcare Bio-Sciences AB, Uppsala, Sweden), the Prolong Antifade kit was from Molecular Probes (Life Technologies, Carlsbad, CA), and the cytotoxicity assay kit was from Promega (Madison, WI).

\section{Synthesis of lipid vinyl sulfone}

Compounds 4, 7, and 9 were prepared according to the procedure described by Morales-Sanfrutos et al. ${ }^{31}$ The ${ }^{1} \mathrm{H}$ nuclear magnetic resonance (NMR) and ${ }^{13} \mathrm{C}$ NMR were analyzed in a $300 \mathrm{MHz}$ Varian Inova Unity with a broadband (13C and $1 \mathrm{H})$ probe.

\section{Preparation of the nanocapsules}

The method used to prepare the nanocapsules was adapted from the technique of Rönnberg et al. ${ }^{32}$

\section{ISCOM matrix}

Thirty milligrams of cholesterol and $30 \mathrm{mg}$ of phosphatidyl choline were mixed by magnetic stirring in $2 \mathrm{~mL}$ of
Milli-Q quality water and $400 \mathrm{mg}$ of MEGA-10; $2.0 \mathrm{~mL}$ of phosphate-buffered saline (PBS) ( $\mathrm{pH} 7.4$ ) was mixed sequentially with $0.8 \mathrm{~mL}$ PC/C stock solution and $0.6 \mathrm{~mL}$ of Quil A $(100 \mathrm{mg} / \mathrm{mL})$ at room temperature (rt) for 1 hour. The final volume was adjusted to $12 \mathrm{~mL}$ by the addition of PBS. The resulting mixtures were dialyzed against water for 48 hours at $4{ }^{\circ} \mathrm{C}$ with frequent changes. The ISCOMs were purified by centrifugation through a sucrose gradient $(10 \%-50 \%$ sucrose in PBS) at 50,000 g (Beckman Ultracentrifuge, JA $30.50 \mathrm{Ti}$. Rotor; Beckman Coulter, Brea, CA) at $4^{\circ} \mathrm{C}$ for 18 hours as according to Papadopoulou et $\mathrm{al}^{33}$ and Myschik et al. ${ }^{34}$ The pellets containing the ISCOMs were resuspended in $200 \mu \mathrm{L}$ PBS and then lyophilized and stored until use.

\section{ISCOM containing phycocyanin: ISCOM-phy}

To incorporate the phycocyanin into the nanocapsules, a $7.5 \mu \mathrm{g} / \mathrm{mL}$ phycocyanin solution was mixed at a proportion of $1: 1 \mathrm{v} / \mathrm{v}$ into the final ISCOM solution. The resulting mixture was dialyzed against water for 48 hours at $4^{\circ} \mathrm{C}$ with frequent changes and the ISCOMs were purified by centrifugation as described below. The phycocyanin content of the ISCOMs was checked by taking a $10 \mu \mathrm{L}$ aliquot of the pellet after the final centrifugation in a discontinuous sucrose gradient at 50,000 $\mathrm{g}$ (as described above), resuspending it in $500 \mu \mathrm{L}$ of water, and measuring spectrophotometrically at $540 \mathrm{~nm}$. The quantities of phycocyanin encapsulated within the ISCOMs were determined by comparison with model curves of known concentrations.

\section{ISCOM with actimomycin D}

When the antibiotic actinomycin D was incorporated into the nanocapsules it was added to the ISCOM mix along with the Quil A $5 \mathrm{mg} / \mathrm{mL}$ as stock solution. The ISCOMs were dialyzed and purified as described above.

After the purification process, to check whether the antibiotic had been properly included in the ISCOMs, a $10 \mu \mathrm{L}$ aliquot was taken, dissolved in methanol, and sonicated for 5 minutes before being dissolved in $10 \mu \mathrm{L}$ of a solution composed of $5 \mathrm{mM}$ of ammonium acetate in water titrated to $\mathrm{pH} 3.5$ with acetic acid:methanol:acetonitrile (50:25:25 $\mathrm{v} / \mathrm{v} / \mathrm{v}$ ) and injected into a Waters Quattro micro GC mass spectrometer (Waters Corp, Milford, MA) equipped with a triple-quad analyzer. Quantification was done spectrophotometrically at $270 \mathrm{~nm}$.

\section{Nanocapsules containing cholesterol-vinyl sulfone: ISCOM-9}

To prepare nanocapsules with compound 9 (Figure 1), we followed the same methods as those just described, but using 

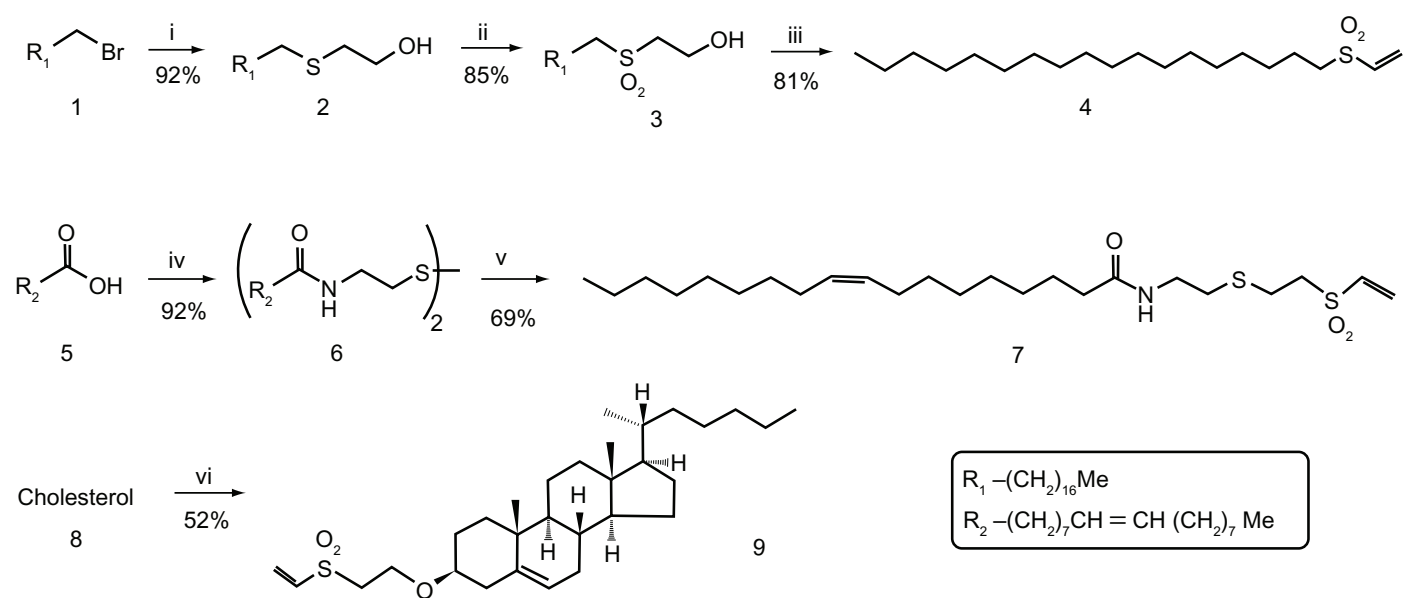

Figure I Synthesis of vinyl-sulfone reagents for the functionalization of nanocapsules. (i) $\mathrm{HS}\left(\mathrm{CH}_{2}\right)_{2} \mathrm{OH}, \mathrm{K}_{2} \mathrm{CO}_{3}$, DMSO-THF (I:I), rt, I6 hours. (ii) $\mathrm{H}_{2} \mathrm{O}_{2}$, AcOH, rt, I6 hours. (iii) methanesulfonyl chloride, $\mathrm{Et}_{3} \mathrm{~N}, \mathrm{CH}_{2} \mathrm{Cl}_{2}$ anh, rt, 24 hours. (iv) (a) $\mathrm{Cl}_{2} \mathrm{SO}, \mathrm{rt}, \mathrm{I}$ hour; (b) cystamine, $\mathrm{Et}_{3} \mathrm{~N}_{2} \mathrm{CH}_{2} \mathrm{C}_{12}$ anh, $\mathrm{rt}, 15$ minutes. (v) (a) $\mathrm{Zn}, \mathrm{AcOH}^{2}, 50^{\circ} \mathrm{C}, 40$ minutes; (b) DVS, Et ${ }_{3} \mathrm{~N}, \mathrm{THF}-\mathrm{PPrOH}(2: 1), \mathrm{rt}, 90$ minutes. (vi) DVS, tBuOK, THF, rt, I hour.

Abbreviations: $\mathrm{AcOH}$, acetic acid; DMSO, dimethyl sulfoxide; DVS, divinyl sulfone; rt, room temperature; THF, tetrahydrofuran.

a mixture of compound 9 and cholesterol at proportions of 1:1 or 2:3 instead of cholesterol alone. The rest of the procedure, both for the preparation of the nanocapsules (ISCOM matrix modified, nanocapsule with phycocyanin, and nanocapsule with actinomycin D) and the purification and measurement of the phycocyanin and actinomycin D contained in them was the same.

The correct formation of the nanocapsules and their size were checked under a C. Zeiss EM 902 transmission electron microscope (Carl Zeiss AG, Oberkochen, Germany) by depositing the suspension on carbon-covered meshes stained with $1 \%$ phosphotungstic acid.

\section{Production of anti-Trypanosoma cruzi antibodies and IgG purification}

We used the hybrids DTU and DTUII of the Maracay strain of Trypanosoma cruzi, deriving from an isolate from a clinical case in Maracay (Venezuela) and maintained by cryopreservation before culturing at $28^{\circ} \mathrm{C}$ in a MTL medium..$^{35}$ After 4 days, when the epimastigote forms had reached the end of the exponential growth phase $\left(2 \times 10^{8}\right.$ parasites $\left./ \mathrm{mL}\right)$, the cultures were centrifuged at $4000 \mathrm{~g}$ for 20 minutes and the pellet was washed in $0.15 \mathrm{M}$ PBS ( $\mathrm{pH}$ 7.4) to eliminate any remains of the culture medium. The parasites were then suspended in lysis buffer (20 mM phosphate buffer [pH 7.4], $1 \mathrm{mM}$ EDTA, $0.25 \mathrm{mM}$ sucrose, $0.145 \mathrm{mM} \mathrm{KCl}, 1 \mathrm{mM}$ DTT, and $1 \% \mathrm{v} / \mathrm{v}$ Triton $\mathrm{X}-100)$ together with $0.003 \%$ antipainhydrochloride, $0.005 \%$ bestatin, $0.001 \%$ cimostatin, $0.003 \%$ E- $64,0.005 \%$ leupeptin, $0.005 \%$ pepstatin, $0.003 \%$ phosphoramidon, $0.2 \%$ pefabloc SC, $0.005 \%$ aprotinin, and $0.1 \%$ EDTA (all $\mathrm{w} / \mathrm{v}$ ) as protease inhibitors. The suspension containing the parasites was frozen at $-80^{\circ} \mathrm{C}$ and thawed three times to $4^{\circ} \mathrm{C}$, followed by sonication for 1 minute at six cycles of 10 seconds at $200-300 \mathrm{~W}$ at $0^{\circ} \mathrm{C}$ in a lysis buffer containing protease inhibitors to break up the cells. The sonicated fraction was centrifuged at 22,000 $\mathrm{g}$ for 30 minutes and the supernatant was collected. The quantity of proteins in the extract of the epimastigote forms was calculated using Bradford's method. ${ }^{36}$

The antiserum against the epimastigote forms was prepared according to the methods described in a previous paper. ${ }^{37} \mathrm{BALB} / \mathrm{c}$ mice were injected intraperitoneally with $50 \mu \mathrm{g}$ of the protein extract mixed with Freund's complete adjuvant, followed by booster injections administered 2 weeks and 4 weeks later with $50 \mu \mathrm{g}$ of protein and Freund's incomplete adjuvant. The mice were bled 2 weeks after the final booster. The sera were checked by indirect enzymelinked immunosorbent assay (ELISA) in multi-well plates coated with $10 \mu \mathrm{g} / \mathrm{well}$ of the epimastigote extract in $0.1 \mathrm{M}$ bicarbonate coating buffer ( $\mathrm{pH} 8.6$ ). Sera with titers higher than $1: 1800$ were pooled and stored at $-80^{\circ} \mathrm{C}$ until use. The IgG was purified by affinity chromatography in a protein A sepharose column (GE) and stored at $-80^{\circ} \mathrm{C}$ until use.

As an IgG control we used purified immunoglobulins from non-immunized animals, the immunofluorescence of which at a serum dilution of 1:100 revealed no reaction against the epimastigote forms of the parasite.

\section{Functionalization of the nanocapsules Incorporation of hydrophobic chains (compounds 4 and 7) into protein A}

Compounds 4 and 7 were solubilized in methanol and mixed with $0.125 \mathrm{mM}$ carbonate buffer $(\mathrm{pH} 8.3)$ to a final 
concentration of $2 \mathrm{mg} / \mathrm{mL}$ each. The solutions of each compound were mixed with a $2 \mathrm{mg} / \mathrm{mL}$ solution of protein $\mathrm{A}$ in carbonate buffer $[0.125 \mathrm{mM}$ carbonate $(\mathrm{pH} 8.3)]$ at a proportion of $1: 1$ and kept at $4{ }^{\circ} \mathrm{C}$ with orbital shaking for 12 hours, after which the free reactive groups of the compounds were blocked with a solution of $4 \mathrm{~mL}$ of $1 \mathrm{M}$ glycine in carbonate buffer at $\mathrm{rt}$ for 4 hours. The conjugates were concentrated using a centrifugal filter device to obtain a total protein concentration of $2 \mathrm{mg} / \mathrm{mL}$.

\section{ISCOMs modified with protein A: ISCOMs-4-A, ISCOMs-7-A}

The suspensions containing the different types of nanocapsules (ISCOM matrix, ISCOM-phy, and ISCOM-actinomycin D) were incubated with the two conjugates (compounds 4-A and 7-A) in a carbonate buffer with orbital shaking at $4^{\circ} \mathrm{C}$ for 1 hour. Any excess of compound-protein A (4-A and 7-A) was eliminated by purifying the nanocapsules by centrifugation as described above.

\section{Conjugation of protein A with compound 9 (ISCOM-9-A)}

Protein A was coupled to compound 9 by direct incubation with ISCOM-9 (ISCOM-matrix-9, ISCOM-9-phy, and ISCOM-9-actinomycin D) in carbonate buffer with orbital shaking at $4^{\circ} \mathrm{C}$ for 1 hour and then incubated with glycine and purified by centrifugation at 50,000 g for 18 hours in a 10 , 25 , and $50 \%$ sucrose gradient, the ISCOM sediments being collected in the pellet and lyophilyzed for later use.

ISCOMs modified with protein A-IgGs: ISCOM-4-AIgGs, ISCOM-7-A-IgGs and ISCOM-9-A-IgGs

A fraction of each of the nanocapsules modified with protein A was bound with different IgGs (mouse anti T. cruzi IgG [IgGsp], mouse IgG negative control, and human IgG [IgG nsp]). The nanocapsules modified with protein A were incubated with the IgGs at a concentration of $40 \mathrm{mg} / \mathrm{mL}$ (10 times the binding capacity of protein A used to link the Fc regions of the IgGs employed) in a carbonate buffer at $\mathrm{rt}$ for 30 minutes. The functionalized nanocapsules were purified once more by centrifugation, as described above, to eliminate any excess of unbound IgGs. Once functionalized, they were analyzed again by TEM as described above.

The various preparations of nanocapsules made with the different compounds, with or without the specific antibodies, were all lyophilyzed until later use. The effectiveness of the binding of the immunoglobulins to the different ISCOMs was determined by immunoenzymatic assay. Samples of the
ISCOMs were also coated onto an ELISA plate and monoclonal antibodies against mouse IgG were used to detect their relative $\mathrm{IgG}$ content. Polystyrene Maxisorp 96-well microtiter plates (Nunc ${ }^{\circledR}$, Roskilde, Denmark) were sensitized for 1 hour at rt with $100 \mu \mathrm{L}$ per well of a suspension of $1 \mathrm{mg} / \mathrm{mL}$ of the nanocapsules containing the immunoglobulins in 0.1 M PBS ( $\mathrm{pH} 7.2$ ). Once sensitized, the plate was washed three times with $0.2 \%$ PBS-Tween (PBS-T) and then incubated with $100 \mu \mathrm{L}$ of a 1:200 dilution of goat anti-mouse Fab conjugated with HRP in PBS for 45 minutes at $37^{\circ} \mathrm{C}$. After incubation with the secondary antibodies the plates were washed four times and an aqueous solution of $0.4 \mathrm{mg} / \mathrm{mL}$ phenylenediamine dihydrochloride in $0.05 \mathrm{M}$ phosphate-citrate buffer ( $\mathrm{pH}$ 5.0) was added as a substrate solution for the peroxidase before further incubation at $\mathrm{rt}$ for 15 minutes. The reaction was stopped with $5 \mu \mathrm{L}$ of a $0.1 \mathrm{M}$ solution of $\mathrm{H}_{2} \mathrm{SO}_{4}$ and the absorbance was measured at $490 \mathrm{~nm}$ in an ELISA Multiskan spectrum reader (Thermo Fisher Scientific, Waltham, MA). ${ }^{14}$ To check that the opticaldensity values corresponded to the mouse IgGs and not to the binding of the anti-mouse antibody to protein A incorporated into the ISCOMs, we conducted a control assay in which the ISCOMs-protein A were bound to human IgGs and incubated with the secondary anti-mouse antibodies labeled with HRP. The IgG binding capacity of the functionalized ISCOM 4 was also determined by ELISA.

\section{Evaluation of ISCOM-phy by fluorescence microscopy}

The parasites used in the assays to observe the binding of the ISCOMs labeled with phycocyanin were cultured under conditions similar to those described above, collected by centrifugation at $1700 \mathrm{~g}$ for 10 minutes at $4{ }^{\circ} \mathrm{C}$ and then washed with PBS. The pellet containing the parasites was fixed in a solution of $4 \%$ formaldehyde and $0.02 \%$ glutaraldehyde at $\mathrm{pH} 8.2$ and $4^{\circ} \mathrm{C}$ in a carbonate buffer for 1 hour and counted in a Neubauer hemocytometer counting chamber. The number of epimastigotes in suspension was adjusted to $2 \times 10^{5} / \mathrm{mL}$ and $20 \mu \mathrm{L}$ samples were then placed on borosilicate glass slides. Once the antigen was dry, the slides were blocked for 30 minutes at $20^{\circ} \mathrm{C}$ in a blocking solution (PBS [pH 7.2], $0.3 \%$ Tween $20,1 \%$ casein, and $0.2 \mathrm{M}$ glycine) before being washed in PBS. They were then incubated for 30 minutes at $20^{\circ} \mathrm{C}$ in a humid chamber with the different suspensions of ISCOMs-phy (ISCOM-phy, ISCOM-phy-A, ISCOM-phy-AIgGs, ISCOM-9-phy, ISCOM-9-phy-A, and ISCOM-9-phyA-IgGs). Finally, they were washed once again in carbonate buffer and treated with Prolong Antifade mounting medium. 
The binding of the nanocapsules labeled with phycocyanin was studied and recorded under a Leica DMI 6000 confocal microscope (Leica Microsystems, Wetzlar, Germany) at $650 \mathrm{~nm}$.

Fluorescence measurements were made using images taken with the ImageJ program (http//:rsb.info.nih.gov/ij; National Institutes of Health, Bethesda, MD).

\section{Actinomycin $D$ activity in the inhibition of cell growth}

To assess the delivery capacity of nanocapsules covered with specific antibodies and loaded with actinomycin D compared to the same antibiotic delivered in a free, nonencapsulated form, we conducted a series of experiments to assess the death rate induced in cultures of the epimastigote form of T. cruzi $\left(1 \times 10^{7}\right.$ parasites $\left./ \mathrm{mL}\right)$ by ISCOM-9-actinomycin D-protein A-IgGs. To this end, epimastigotes in the exponential-growth phase were adjusted to $1 \times 10^{7} / \mathrm{mL}$ and $200 \mu \mathrm{L}$ aliquots were placed in the wells of a cell-culture microplate; 5,15 , or $30 \mu \mathrm{L}$ aliquots of the nanocapsule suspension were added and left for 2 hours. The plate was then centrifuged at $250 \mathrm{~g}$ for 10 minutes and the sediments washed with fresh medium to eliminate any nanocapsules remaining unbound. The sediment was subsequently incubated at $28^{\circ} \mathrm{C}$ for 24 hours and the cytotoxicity of the wells was assessed after treatment with a CytoTox 96 non-radioactive cytotoxicity assay kit (Promega), which measures the release into the medium of the enzyme lactate dehydrogenase present in the cytoplasm of intact cells. Each of the assays was repeated in triplicate. The cytotoxicity of each well was tested colorimetrically at $490 \mathrm{~nm}$ in a MultisKan Spectrum plate reader (Thermo Fisher Scientific) according to the manufacturer's instructions.

\section{Statistical analysis}

A Tukey-Kramer multiple comparisons test was used to estimate the significance of the difference between means. The results are indicated as mean values (standard errors of the mean of the different groups at different times for each experiment performed were determined). All the experiments were repeated three times; $P<0.001$ was considered to be extremely significant. GraphPad Instat v3.05 (GraphPad Software, Inc, La Jolla, CA) software was used for the statistical testing.

\section{Results}

\section{Synthesis of vinyl-sulfone reagents}

Various different compounds containing hydrophobic chains and vinyl-sulfone functionality for conjugation with the amino groups present in protein A were prepared according to the procedure described by Morales-Sanfrutos et al. Starting from 1-bromooctadecane (1), oleic acid (5), and cholesterol (8), respectively, simple chemical strategies allowed us to obtain good yields of their corresponding vinyl-sulfone derivatives (Figure 1). Thus, nucleophilic displacement of the bromide derivative 1 with 2 -thioethanol followed by oxidation with peroxyacetic acid and subsequent dehydration led easily to compound 4 . Compound 7 was obtained by making oleic-acid chloride react with cystamine and reducing the disulfide thus obtained with powdered $\mathrm{Zn}$, followed by Michael addition to divinyl sulfone in a one-step procedure. Finally, the simple treatment of commercial cholesterol with divinyl sulfone under basic conditions afforded a moderate yield of the corresponding vinyl-sulfone derivative, compound 9.

${ }^{1} \mathrm{H}$ and ${ }^{13} \mathrm{C}$ NMR spectra confirm the structures of compounds 4, 7, and 9 (see Supplementary materials).Product yields are indicated in Figure 1. Additionally, NMR spectra of compounds 4, 7, and 9 are included in the Supplementary material.

\section{Characterization of the nanocapsules}

The shape, morphology, homogeneity, and size of the nanocapsules were checked by transmission electron microscopy (see Figure 2) according to Papadopoulou et al..$^{33}$ The particles formed by the three functionalized compounds 4, 7, and 9, showed an average size of $37 \mathrm{~nm}$, appeared to be homogeneous, and with characteristics proper to those of an ISCOM, showing the typical shape of this type of nanocapsule.

When phycocyanin was encapsulated in the nanocapsules, ISCOMs charged with dye were obtained, as can be seen in the confocal micrographs in Figure 3, which, when anchored to the surface of the epimastigote forms of the parasite, showed phycocyanin fluorescence when excited at $620 \mathrm{~nm}$.

Encapsulation of actinomycin D in the ISCOMs was checked by mass spectrometry after the nanocapsules had been purified by centrifugation in a gradient. The antibiotic was found in the pellet along with the nanocapsules. Evaluation by spectrophotometry revealed that the concentration of antibiotic was $0.192 \mu \mathrm{g} / \mathrm{mL}$ when the pellet was diluted at $1: 1 \mathrm{w} / \mathrm{v}$ in PBS. The same suspension was used in subsequent experiments to assess its effect on the epimastigote forms of the parasite.

\section{Evaluation of bound $\operatorname{lgGs}$}

The evaluations by ELISA of the IgGs bound to the nanocapsules are set out in Figure 4, in which it can be seen 

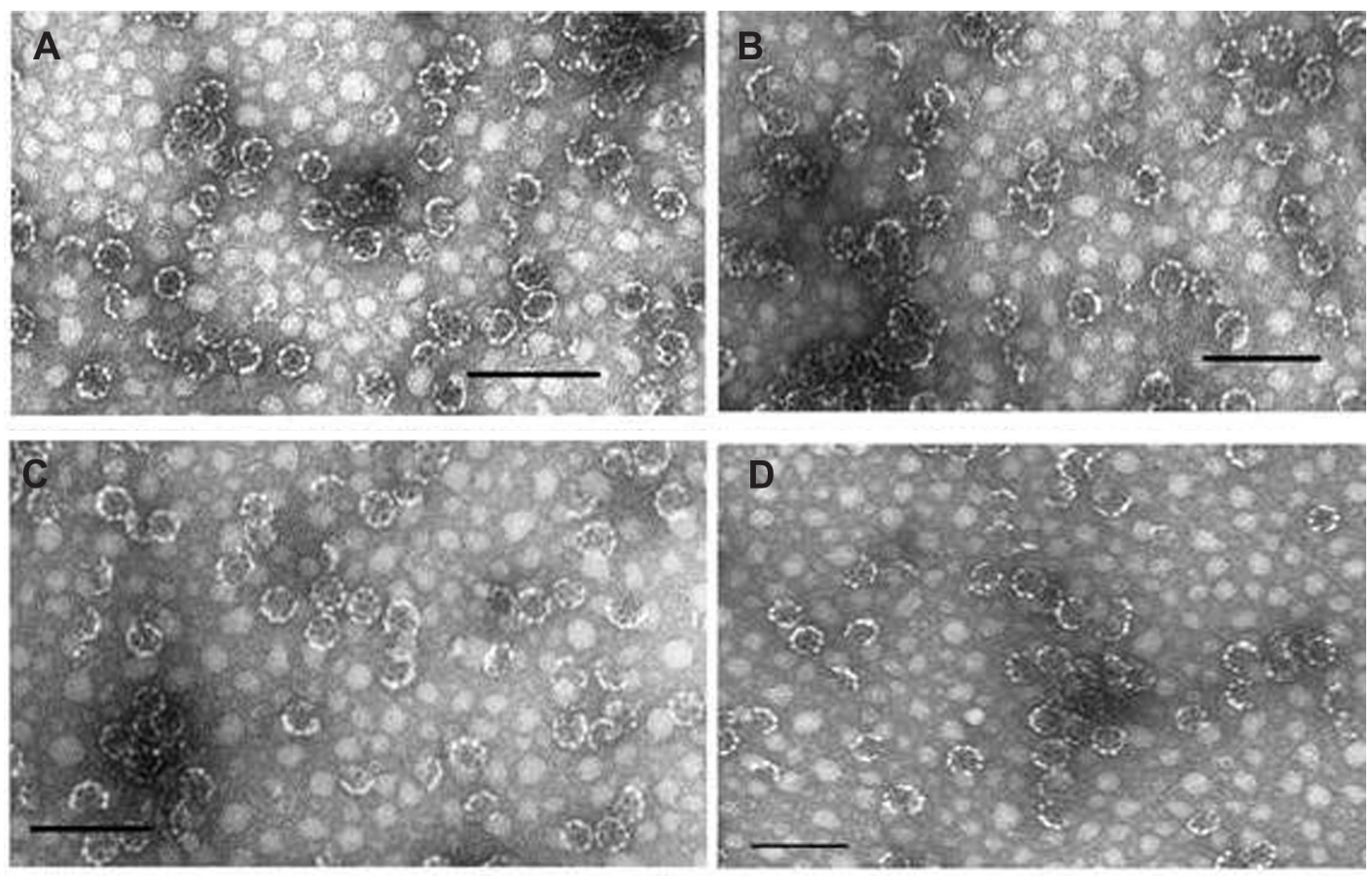

Figure 2 Transmission electron microscope images. (A) ISCOM-matrix. (B) ISCOM-phy-7-A-lgG-specific. (C) ISCOM-4-A-lgG-specific containing actinomycin D. (D) ISCOM-9-A-lgG specific IgGs.

Note: $\mathrm{Bar}=150 \mathrm{~nm}$.

Abbreviations: IgG, immunoglobulin; ISCOM, immunostimulating complex.

that the compounds containing vinyl-sulfone groups and hydrophobic chains $(4,7$, or 9$)$ simultaneously are capable of incorporating the IgGs by different strategies; functionalized long alkyl chains and those containing functionalized cholesterol are both capable of incorporating the different IgGs, either by binding to protein A, which had previously been anchored to the compounds with vinyl sulfone 4 or 7 , or by binding directly to the functionalized cholesterol (compound 9).

The results suggest that the lipophilic part of vinylsulfone compounds 4 and 7 is inserted into the wall of the nanocapsules, where the presence of functional protein $A$ was observed by its binding to the immunoglobulins linked to the vinyl-sulfone/protein A complex. In the case of compound 9, protein A is bound directly to the compound already inserted into the wall of the nanocapsule.

Only the controls, unbound ISCOMs, and those bound to human IgGs instead of mouse IgGs, were not recognized by the secondary anti-mouse antibodies, which proves that the colorimetric reaction can be put down to the mouse IgGs bound to protein $\mathrm{A}$ inserted into the nanocapsules rather than to the binding of the immunoglobulins that form part of the secondary antibody to protein A.

The average binding efficiency of IgG to the ISCOM 4 evaluated by ELISA was $0.034 \mu \mathrm{g}$ of IgG per $1 \mu \mathrm{g}$.
When nanocapsules containing phycocyanin were used, whether bound to antibodies specific or not to the forms of the parasite, maximum fluorescence intensities, as observed under a confocal microscope, were always obtained when the specific IgG's deriving from the immunization were bound to the nanocapsules.

The fluorescence levels of all the preparations with the control ISCOMs (ie, those not bound to any antibodies specific against $T$. cruzi or where purified IgGs not specific to the parasite were used) were close to zero. In those preparations in which the specific immunoglobulins were bound to the surface of the nanocapsules, on the other hand, the fluorescence levels were between 12 and 19 times higher than the controls, which indicates that the IgGs are anchored to the surface of the nanocapsules and that their functionality depends upon their Fab regions recognizing the epitopes of the parasite antigens. The fluorescence levels measured in the different assays are set out in Table 1, Figures 3 and 5 .

\section{Cytotoxicity assays}

The cytotoxicity data after 24 hours' treatment, showing a comparison between the toxicity of free actinomycin D $(50 \mathrm{ng} / \mathrm{mL})$ and that of the different concentrations of antibiotic encapsulated in the nanocapsule ISCOM-9-actinomycin D-A-IgGsp, are set out in Figure 6. 


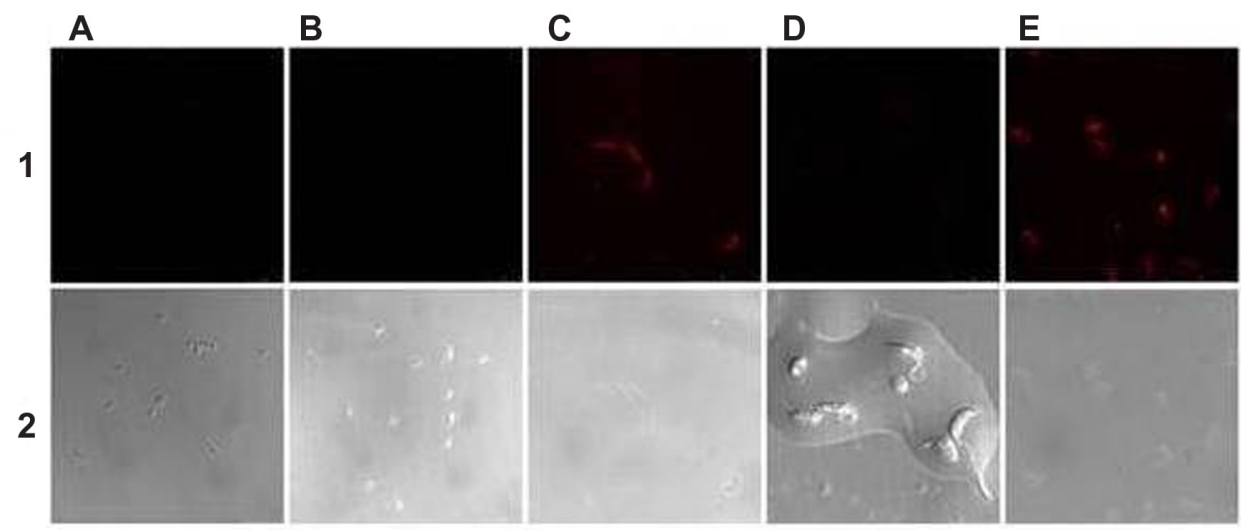

Figure 3 Laser confocal micrographs of epimastigotes of Trypanosoma cruzi incubated with different phycocyanin nanocapsules. (A) ISCOM-phy; (B) ISCOM-phy-4-A; (C) ISCOM-phy-4-A-IgGsp; (D) ISCOM-phy-7-A; (E) ISCOM-phy-7-A-IgGsp.

Notes: (I) Laser confocal and (2) phase contrast microscope images.

Abbreviations: IgG, immunoglobulin; IgGsp, IgG specific; ISCOM, immunostimulating complex; phy, phycocianin.

A correlation of the cytotoxicity induced in T. cruzi against the dose of antibiotic contained in the functionalized nanocapsules bound to specific protein A-IgG gave a linear regression with $r=0.9801$, with a theoretical inhibition of $100 \%$ at a dose of $25.47 \times 10^{-2} \mathrm{ng} / \mathrm{mL}$ of actinomycin $\mathrm{D}$.

\section{Discussion}

ISCOMs are rigid, lipid nanosomes in the shape of hollow pentagonal dodecahedrons about $40 \mathrm{~nm}$ in diameter,

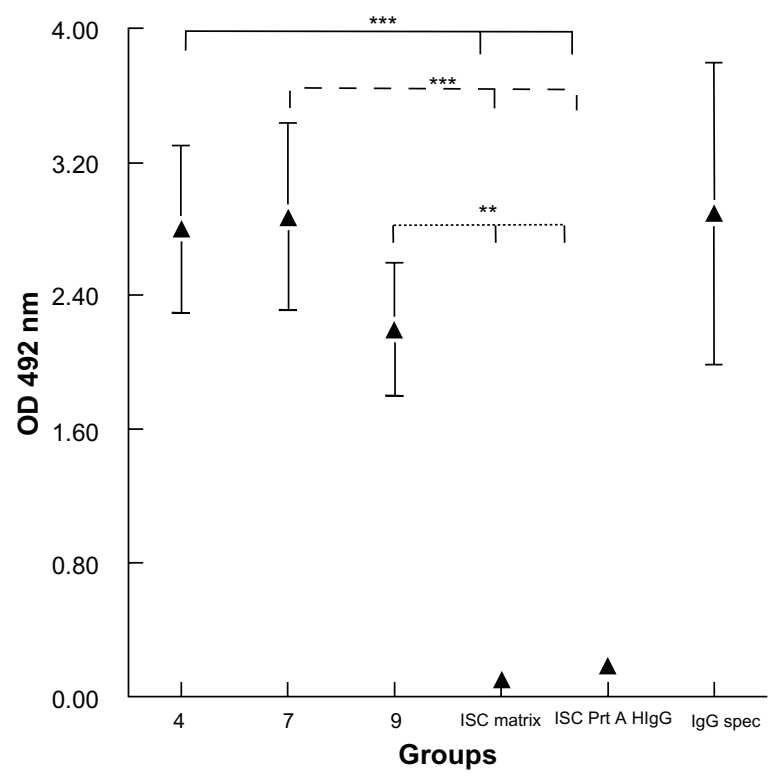

Figure 4 Evaluation of bound IgGs.

Notes: Determination with ELISA of the immunoglobulins bound to the nanoparticles via a secondary anti-mouse antibody labeled with peroxidase. The results are the mean of three experiments \pm standard error of the mean. **P $<0.01$ Tukey-Kramer multiple comparisons test; $* * * P<0.001$. 4, ISCOM with compound 4 linked to mouse Prot A-lgG; 7, ISCOM with compound 7 linked to Prot A bound to mouse lgG; 9 , ISCOM formed with compound 9 (I:I) linked to Prot A bound to mouse IgG; ISC matrix, ISCOM-matrix; ISC Prt A H IgG, ISCOM with compound 4 linked to Prot $A$ and human $\operatorname{lgG}$; $\lg \mathrm{g}$ spec, mouse $\lg \mathrm{G}$ obtained after immunization with Trypanosoma cruzi. Abbreviations: IgG, immunoglobulin; ISCOM, immunostimulating complex; OD, optical density; Prot A, protein A. originally developed as carriers in immunization systems. ${ }^{9}$ They constitute nanosystems for antigenic presentation in which the proteins of the antigens bind to the nanocapsules via the hydrophobic domains of their sequences. This aspect of their activity does, however, present a serious disadvantage for hydrophilic proteins or peptides. We have attempted to solve this drawback by designing a system capable of binding

Table I Relative fluorescence of the different immunostimulating complex (ISCOM) preparations

\begin{tabular}{lc}
\hline Sample & Relative fluorescence (mean \pm SD) \\
\hline ISCOM-phy & $0.034 \pm 0.01$ \\
ISCOM-phy7-A & $0.058 \pm 0.02$ \\
ISCOM-phy4-A & $0.05 \pm 0.01$ \\
ISCOM-phy7-A-IgGsp & $16.477 \pm 0.45^{* * *}$ \\
ISCOM-phy4-A-IgGsp & $14.03 \pm 0.12^{* * *}$ \\
ISCOM-9-phy-Aa & $0.02 \pm 0.01$ \\
ISCOM-9-phy-A-lgGspa & $19.501 \pm 0.31 * * *$ \\
ISCOM-9-phy-Ab & $0.03 \pm 0.01$ \\
ISCOM-9-phy-A-IgGspb & $12.09 \pm 0.12^{* * *}$ \\
ISCOM-phy7-A-IgG non-sp & $0.5 \pm 0.16$ \\
ISCOM-phy4-A-IgG non-sp & $0.03 \pm 0.01$ \\
ISCOM-9-phy-A-IgG non-spa & $0.058 \pm 0.02$
\end{tabular}

Note: $* * * * P<0.001$ by the Tukey-Kramer multiple comparisons test, between the samples without specific $\mathrm{G}$ immunoglobulin $(\mathrm{lgG})$.

Abbreviations: IgG, immunoglobulin; ISCOM-phy, ISCOM labelled with phycocyanin; ISCOM-phy 7-A, protein A bound to ISCOM-phy with compound 7; ISCOM-phy 4-A, protein A bound to ISCOM-phy with compound 4; ISCOM-phy 7-A-IgGsp, ISCOMphy, compound 7 with protein A and Trypanosoma cruzi-specific mouse IgG; ISCOMphy 4-A-IgGsp, ISCOM-phy, compound 4 with protein A and T. cruzi-specific mouse IgG; ISCOM-9-phy-Aa, ISCOM-phy prepared with modified cholesterol (compound 9 at a ratio of $I: I)$ and protein A; ISCOM-9-phy-A-IgGspa, ISCOM-phy prepared with modified cholesterol (compound 9 at a ratio of $\mathrm{I}: \mathrm{I}$ ) and protein $\mathrm{A}$ and T. cruzi-specific mouse IgG; ISCOM-9-phy-Ab, ISCOM-phy prepared with modified cholesterol (compound 9 at a ratio of 2:3) with protein A; ISCOM-9-phy-A-IgGspb, ISCOM-phy prepared with modified cholesterol (compound 9 at a ratio of 2:3) with protein A and T. cruzi-specific mouse IgG; ISCOM-phy 7-A-IgG non-sp ISCOMphy prepared with compound 7, protein $A$ and nonspecific human $\operatorname{lgG}$; ISCOM-phy 4-A-IgG non-sp, ISCOM-phy prepared with compound 4, protein A and nonspecific human IgG; ISCOM-9-phy-A-IgG non-sp, ISCOM-phy prepared with modified cholesterol (compound 9 at a ratio of 2:3), protein $A$ and nonspecific human IgG. 

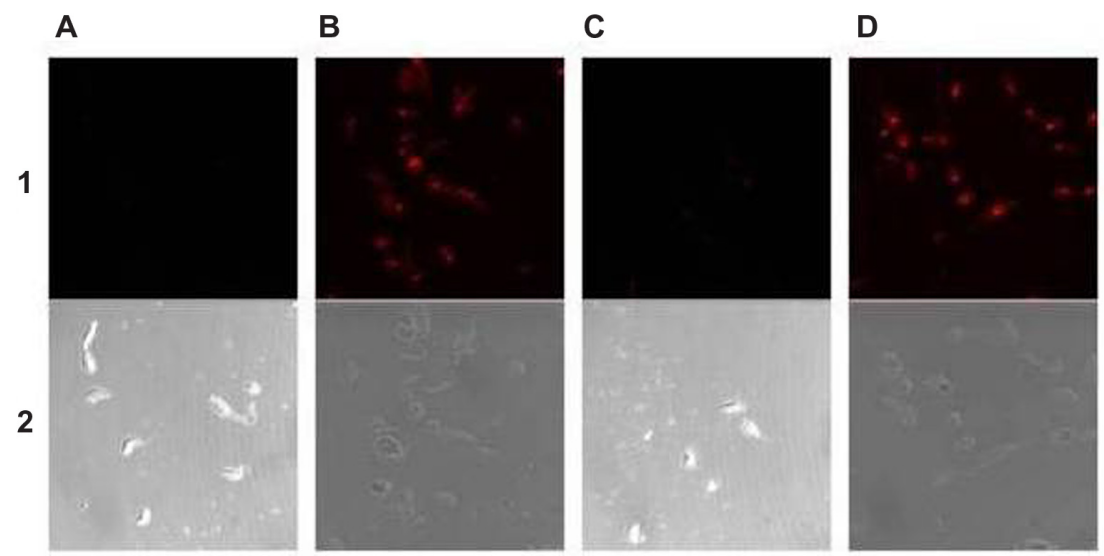

Figure 5 Laser-confocal micrograph of epimastigotes of Trypanosoma cruzi incubated with nanocapsules formed with compound 9. (A) ISCOM-9-phy-A (I:I). (B) ISCOM-9phy-A-IgGsp (I:I). (C) ISCOM-9-phy-A (2:3). (D) ISCOM-9-phy-A-IgGsp (2:3).

Notes: Immunostimulating complex (ISCOM)-9-phycocianin (phy)-A (I:I), nanocapsules formed with compound 9-cholesterol (I:I) with phy linked to protein A (Prot A) without specific G immunoglobulin (IgG); ISCOM-9-phy-A-IgGsp (I:I), nanocapsules formed with compound 9-cholesterol (I:I) with phycocianin linked to specific Prot A IgG; ISCOM-9-phy-A(2:3), nanocapsules formed with compound 9-cholesterol (2:3) with phycocianin linked to Prot A without specific IgG; ISCOM-9-phy-A-IgGsp (2:3), nanocapsules formed with compound 9-cholesterol (2:3) with phycocianin linked to Prot A specific lgG; I, Laser confocal; 2, phase contrast microscope images.

the proteins to ISCOMs via their amino or thiol groups by using novel compounds made up of a lipid chain bound to a vinyl sulfone group (compounds 4, 7, and 9) synthesized specifically for this purpose. First, 4- or 7-vinyl sulfones are able to covalently modify protein $\mathrm{A}$ and thus it can be

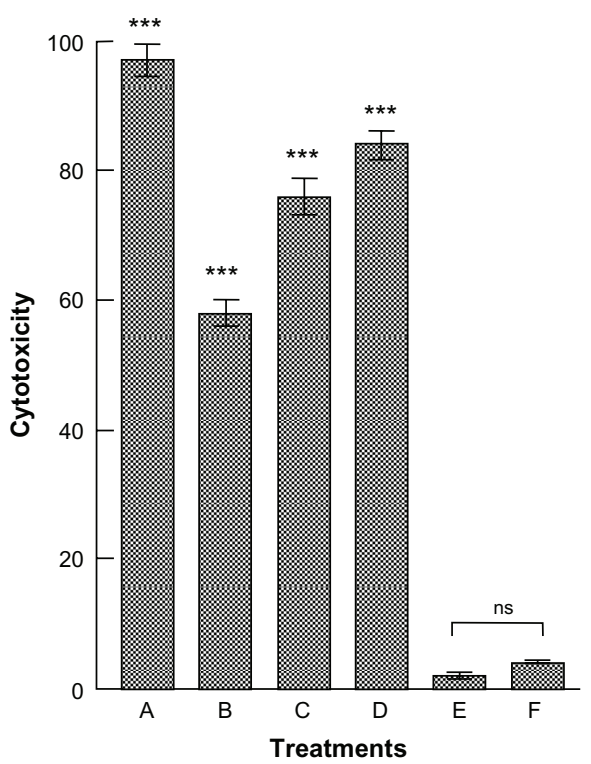

Figure 6 Cytotoxicity + against epimastigote forms of Trypanosoma cruzi measured after 24 hours treatment with actinomycin $D$ contained in functionalized nanocapsules bound to $\mathrm{lgGs}$. (A) Epimastigotes of T. cruzi treated with $50 \mathrm{ng} / \mathrm{mL}$ of actinomycin D. (B) Epimastigotes of T. cruzi treated with ISCOM-9-actinomycin D-A-IgGsp containing $0.15 \times 10^{-2} \mathrm{ng} / \mathrm{mL}$ of actinomycin D. (C) Epimastigotes of $T$. cruzi treated with ISCOM-9-actinomicyn D-A-IgGsp containing $2.88 \times 10^{-2} \mathrm{ng} / \mathrm{mL}$ of actinomycin D. (D) Epimastigotes of T. cruzi treated with ISCOM-9- actinomycin D-A-IgGsp containing $5.76 \times 10^{-2} \mathrm{ng} / \mathrm{mL}$ of actinomycin D. (E) Control culture of untreated epimastigote forms of T. cruzi. (F) Control culture of epimastigote forms of T. cruzi treated with functionalized nanocapsules without actinomycin D ISCOM-9-matrix A-lgG specific against the parasite. Notes: The results are the mean of three experiments \pm standard error of the mean. ns $=P>0.05 ; * * * P<0.001$ Tukey-Kramer multiple comparisons test.

Abbreviations: IgG, immunoglobulin; ISCOM, immunostimulating complex; ns, not significant. anchored to an ISCOM due to hydrophobic interactions (strategy A) (Figure 7A). Alternatively, an ISCOM prepared with cholesterol-vinyl sulfone compound 9 gives rise to functionalized nanocapsules that can bind protein A covalently by simple incubation (strategy B) (Figure 7B). Both strategies lead to similar results, although strategy B offers some advantages over strategy A in terms of its versatility. Vinyl-sulfone functionalized ISCOM obtained by strategy B could be modified by incorporating other molecules instead of protein A, thus avoiding any need for previous incubation with lipidic compounds 4 or 7 .

ISCOMs obtained by either strategy and incorporating protein A are subsequently modified with IgG. This integration of proteins opens the way to using these nanocapsules to deliver their content of drugs, nucleic acids, antibodies, or specific ligands to precise sites to enable them to bind to the membranes of pathogens or tumoral cells. Other than this, they might be used in targeted immunization systems to allow the release of antigens to dendritic cells, for example, or in any other application requiring the use of antibodies and enzymatic or fluorescent labels for immunodiagnostic purposes.

As explained in the Results section, we conducted assays using both strategies, one aimed at binding proteins to the fatty-acid-bearing compounds 4 and 7 by a treatment undertaken after the preparation of the ISCOMs, without altering the size or shape of the nanocapsules. In the same way, compound 9 (Figure 8), corresponding to the structure made up of cholesterol functionalized with the vinyl-sulfone group inserted into the nanocapsule during its preparation, led to the typical ISCOM shape, which remained unaltered 


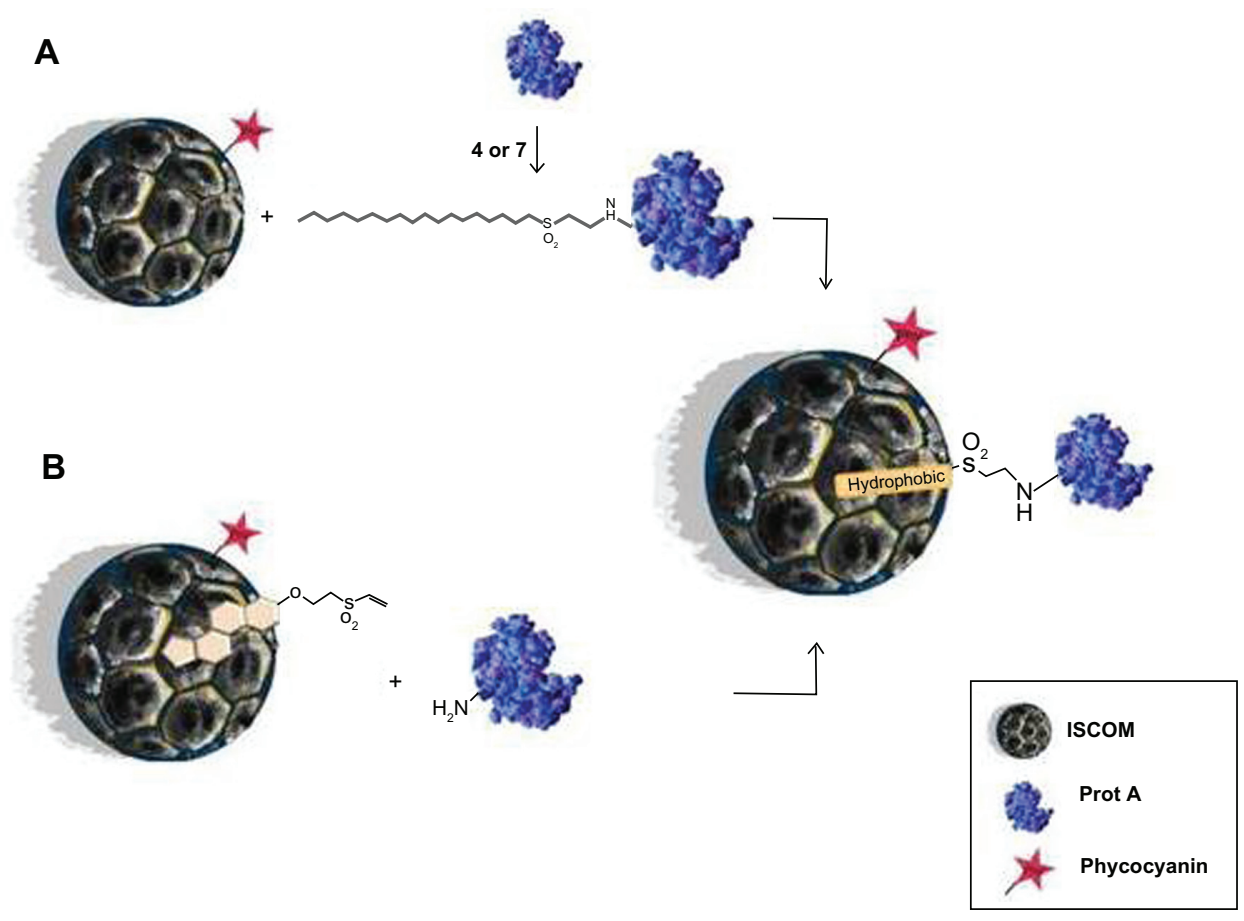

Figure 7 Schematic representation of the ISCOM with compounds 4, 7, or 9 linked to protein A. Abbreviations: ISCOM, immunostimulating complex; Prot A, protein A.

when proteins were subsequently bound to it. Other assays (not shown) revealed that the stability and functionality of ISCOMs prepared in this way remained intact under laboratory conditions even when they were lyophilized and kept at $\mathrm{rt}$ for 3 months before being reconstituted for experimental use, since they maintained their cytotoxic activity throughout this time.

Staphylococcal protein A is a surface protein with an aptitude for binding rapidly with the immunoglobulins of numerous mammals. ${ }^{38}$ It is about $42 \mathrm{kDa}$ in size and contains five highly conserved domains in tandem (E, D, A, B, and C) which can bind to the conserved, or Fc, region of IgGs. ${ }^{39}$ This has led to its being widely used in chromatographic purification processes involving immunoglobulin, or else in their labeling. ${ }^{40}$ Protein A's region $\mathrm{X}$, of about $14 \mathrm{kDa}$, makes up the $\mathrm{COOH}$ terminal region and is unable to bind IgGs, which remain anchored to the membrane of Staphylococcus. ${ }^{41}$ The aza-Michael-type addition of vinyl-sulfone derivatives of these hydrophobic compounds was thought to be an optimum tool to promote their binding with the amino groups in the Lys, Cys, or His residues of protein A, as this reaction usually proceeds very efficiently, without forming any

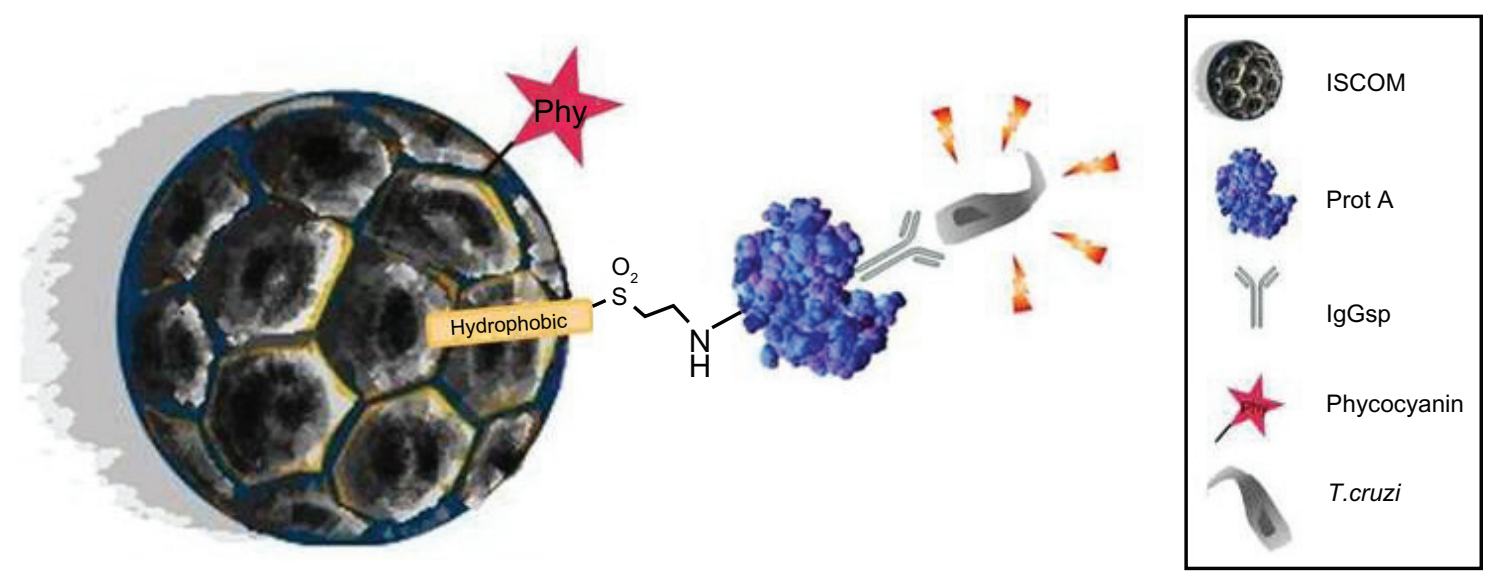

Figure 8 Graphical abstract of the ISCOM with the compounds linked to protein A-IgG.

Abbreviations: IgG, immunoglobulin; IgGsp, IgG specific; ISCOM, immunostimulating complex; Prot A, protein A; T. cruzi, Trypanosoma cruzi. 
undesired by-products, simply by mixing the reagents in a suitable solvent. In this case, the binding of the compounds to protein A must take place mainly through region $\mathrm{X}$ because of the number of lysines it contains; in fact, out of a total of 69 lysine residues, 26 are found in the $\mathrm{X}$ region. ${ }^{41,42}$ Because protein $\mathrm{A}$ is in a functional form when attached to compounds 4,7 , or 9, the E, D, A, and C regions remain free and able to capture the IgGs via the Fc regions of the antibodies, which allows the variable Fab regions of the immunoglobulins to interact with the epitopes of the antigen.

Our results reveal that, after incubating the different types of functionalized nanocapsules bound to protein A with specific immunoglobulins, the relative fluorescence levels are $15.52 \pm 1.60$ units, whereas the functionalized nanocapsules bound either to nonspecific immunoglobulins or without immunoglobulins give fluorescence values close to zero $(0.097 \pm 0.05)$. From this we deduce that the ISCOMs are capable of binding to the functional immunoglobulins without hindering their recognition in any way and anchoring to the epitopes of the antigens on the surface of the epimastigote forms of the parasite (Table 1). The results also verify the delivery capacity of both the ISCOMs bound to immunoglobulins and those containing phycocyanin, and prove that the binding of specific IgGs to the protein A-vinylsulfone compounds was stable, because, when human IgGs were bound, the secondary anti-mouse antibodies failed to recognize them. This ratifies, on the one hand, the binding between $\mathrm{IgG}$ and the protein A-vinyl-sulfone compounds and, on the other, that the positive results cannot be put down to the proteins of the secondary antibody binding to the functionalized ISCOMs.

It is well known that actinomycin D inhibits RNA synthesis and thus the synthesis of proteins. ${ }^{43,44}$ The antibiotic's activity against $T$. cruzi depends on its inhibiting the parasite's multiplication and even decreasing its infectivity against vertebrate host cells, ${ }^{45}$ being capable of blocking RNA synthesis in the parasite within 24 hours at a dose of $10 \mu \mathrm{g} / \mathrm{mL} .{ }^{46}$ Our results show that a $50 \mathrm{ng} / \mathrm{mL}$ dose of actinomycin $\mathrm{D}$ delivered in free form was capable of killing the parasite within 24 hours, whilst the various concentrations of the antibiotic encapsulated in functionalized ISCOMs produced dose-dependent effects with a linear relationship close to $1(r=0.9801)$, achieving, by interpolation, $100 \%$ effectiveness at a dose of $25.47 \times 10^{-2} \mathrm{ng} / \mathrm{mL}$, or 196.8 times lower than that required when given in free form.

The functionalized ISCOMs incubated under identical conditions, but in which the IgGs were not specific, did not prove toxic to the epimastigote forms of T. cruzi and so we could rule out the possibility that the vinyl sulfone itself employed in the preparation of the ISCOM exerted any toxic effect on the parasites, although some authors ${ }^{47}$ have reported that it deactivates the cysteine proteases necessary for the parasite's survival. The fact that vinyl sulfone binds to protein A and then to the ISCOMs, just as the treatment with glycine to block the unreacted vinyl-sulfone groups, would inhibit the potential toxicity of these reactive groups. At the same time it would favor the hydrophilia of the ISCOMs themselves, which would render them invisible to macrophages, unlike the hydrophobic surface of conventional nanoparticles, together with their high curvature $(<100 \mathrm{~nm})$, which reduces opsonization reactions and allows them to elude capture (the inconvenient fate of many lipid nanocapsules described in the literature) and remain for longer in the bloodstream. ${ }^{48}$

It may be concluded then that these types of nanocapsules, functionalized with compounds containing a vinyl sulfone and a hydrophobic chain, such as compounds 4,7 , or 9 , are capable of binding proteins or any other kind of receptor or ligand susceptible to reaction with vinyl sulfones, and are suitable for use as delivery systems in directional therapy, in which specific antibodies or ligands are required to carry drugs directly to their targets, thus increasing their effectiveness whilst at the same time reducing drastically their dosage and their toxicity to the body in general, which is often a drawback in conventional therapy.

\section{Conclusion}

We have constructed functionalized ISCOM-type nanocapsules with lipid vinyl sulfones capable of binding functional IgGs on their surfaces, which favors the recognition and transport of these nanocapsules to specific cells.

\section{Acknowledgments}

This research was financed by Spanish Ministry of Science and Technology grants AGL2011-26098 and CTQ201129299-CO2-01. The authors thank J Trout of the University of Granada Scientific Translation Service for the English translation of their text.

\section{Disclosure}

The authors report no conflicts of interest in this work.

\section{References}

1. Gregoriadis G. Enzyme-carrier potential of liposomes in enzyme replacement therapy. N Engl J Med. 1975;292(4):215.

2. Gregoriadis G. Homing of liposomes to target cells. Biochem Soc Trans. 1975;3(5):613-618. 
3. Gregoriadis G, Neerunjun ED. Treatment of tumour bearing mice with liponsome-entrapped actinomycin D prolongs their survival. Res Commun Chem Pathol Pharmacol. 1975;10(2):351-362.

4. Segal AW, Gregoriadis G, Black CD. Liposomes as vehicles for the local release of drugs. Clin Sci Mol Med. 1975;49(2):99-106.

5. Singh M, Chakrapani A, O'Hagan D. Nanoparticles and microparticles as vaccine-delivery systems. Expert Rev Vaccines. 2007;6(5):797-808.

6. Lövgren Bengtsson K, Morein B, Osterhaus AD. ISCOM technologybased Matrix $\mathrm{M}^{\mathrm{TM}}$ adjuvant: success in future vaccines relies on formulation. Expert Rev Vaccines. 2011;10(4):401-403.

7. Sun HX, Xie Y, Ye YP. ISCOMs and ISCOMATRIX. Vaccine. 2009; 27(33):4388-4401.

8. Björkman C, Lundén A, Holmdahl J, Barber J, Trees AJ, Uggla A. Neospora caninum in dogs: detection of antibodies by ELISA using an iscom antigen. Parasite Immunol. 1994;16(12):643-648.

9. Chanlun A, Emanuelson U, Aiumlamai S, Björkman C. Variations of Neospora caninum antibody levels in milk during lactation in dairy cows. Vet Parasitol. 2006;141(3-4):349-355.

10. Lövgren K, Morein B. The requirement of lipids for the formation of immunostimulating complexes (iscoms). Biotechnol Appl Biochem. 1988;10(2):161-172.

11. Slotved HC, Jensen L, Lind P. Comparison of the IFAT and IscomELISA response in bovine foetuses with Neospora caninum infection. Int J Parasitol. 1999;29(8):1165-1174.

12. Morein B, Sundquist B, Höglund S, Dalsgaard K, Osterhaus A. Iscom, a novel structure for antigenic presentation of membrane proteins from enveloped viruses. Nature. 1984;308(5958):457-460.

13. Pandey RS, Babbar AK, Kaul A, Mishra AK, Dixit VK. Evaluation of ISCOM matrices clearance from rabbit nasal cavity by gamma scintigraphy. Int J Pharm. 2010;398(15):231-236.

14. Solano-Parada J, Gonzalez-Gonzalez G, Torró LM, et al. Effectiveness of intranasal vaccination against Angiostrongylus costaricensis using a serine/threonine phosphatase $2 \mathrm{~A}$ synthetic peptide and recombinant antigens. Vaccine. 2010;28(32):5185-5196.

15. Kodama S, Hirano T, Noda K, Umemoto S, Suzuki M. Nasal immunization with plasmid DNA encoding P6 protein and immunostimulatory complexes elicits nontypeable Haemophilus influenzae-specific longterm mucosal immune responses in the nasopharynx. Vaccine. 2011; 29(10):1881-1890.

16. Björkman C, Jakubek EB, Arnemo JM, Malmsten J. Seroprevalence of Neospora caninum in gray wolves in Scandinavia. Vet Parasitol. 2010; 173(1-2):139-142.

17. Frössling J, Bonnett B, Lindberg A, Björkman C. Validation of a Neospora caninum iscom ELISA without a gold standard. Prev Vet Med. 2003;57(3):141-153.

18. Malmsten J, Jakubek E-B, Björkman C. Prevalence of antibodies against Toxoplasma gondii and Neospora caninum in moose (Alces alces) and roe deer (Capreolus capreolus) in Sweden. Vet Parasitol. 2011;177(3-4): 275-280.

19. Kensil CR. Saponins as vaccine adjuvants. Crit Rev Ther Drug Carrier Syst. 1996;13(1-2):1-55.

20. Kersten GF, Spiekstra A, Beuvery EC, Crommelin DJ. On the structure of immune-stimulating saponin-lipid complexes (iscoms). Biochim Biophys Acta. 1991;1062(2):165-171.

21. Kersten GF, Teerlink T, Derks HJ, et al. Incorporation of the major outer membrane protein of Neisseriagonorrhoeae in saponin-lipid complexes (iscoms): chemical analysis, some structural features, and comparison of their immunogenicity with three other antigen delivery systems. Infect Immun. 1988;56(2):432-438.

22. Akerblom L, Nara P, Dunlop N, Putney S, Morein B. HIV experimental vaccines based on the iscom technology using envelope and GAG gene products. Biotechnol Ther. 1993;4(3-4):145-161.

23. Heeg K, Kuon W, Wagner H. Vaccination of class I major histocompatibility complex (MHC)-restricted murine CD8+ cytotoxic T lymphocytes towards soluble antigens: immunostimulating-ovalbumin complexes enter the class I MHC-restricted antigen pathway and allow sensitization against the immunodominant peptide. Eur J Immunol. 1991;21(6):1523-1527.
24. Sjölander S, Hansen JE, Lövgren-Bengtsson K, Akerblom L, Morein B. Induction of homologous virus neutralizing antibodies in guinea-pigs immunized with two human immunodeficiency virus type 1 glycoprotein gp120-iscom preparations. A comparison with other adjuvant systems. Vaccine. 1996;14(4):344-352.

25. Mowat AM, Donachie AM, Reid G, Jarrett O. Immune-stimulating complexes containing Quil A and protein antigen prime class I MHCrestricted $\mathrm{T}$ lymphocytes in vivo and are immunogenic by the oral route. Immunology. 1991;72(3):317-322.

26. Meadows DC, Gervay-Hague J. Vinyl sulfones: synthetic preparations and medicinal chemistry applications. Med Res Rev. 2006;26(6): 793-814.

27. Simpkins NS. The chemistry of vinyl sulphones. Tetrahedron. 1990; 46(20):6951-6984.

28. Lopez Jaramillo F, Hernandez Mateo F, Santoyo Gonzalez F. Vinyl sulfone: a multi-purpose function in proteomics. In: Eastwood Leung H-C, editor. Integrative Proteomics. Croatia: InTech; 2012:301-326.

29. Morales-Sanfrutos J, Lopez-Jaramillo J, Ortega-Muñoz M, et al. Vinyl sulfone: a versatile function for simple bioconjugation and immobilization. Org Biomol Chem. 2010;8(3):667-675.

30. Sarada R, Pillai MG, Ravishankar GA. Phycocyanin from Spirulina sp: influence of processing of biomass on phycocyanin yield, analysis of efficacy of extraction methods and stability studies on phycocyanin. Process Biochemistry. 1999;34(8):795-801.

31. Morales-Sanfrutos J, Megia-Fernandez A, Hernandez-Mateo F, GironGonzalez MD, Salto-Gonzalez R, Santoyo-Gonzalez F. Alkyl sulfonyl derivatized PAMAM-G2 dendrimers as nonviral gene delivery vectors with improved transfection efficiencies. Org Biomol Chem. 2011;9(3): $851-864$.

32. Rönnberg B, Fekadu M, Morein B. Adjuvant activity of non-toxic Quillaja saponaria Molina components for use in ISCOM matrix. Vaccine. 1995;13(14):1375-1382.

33. Papadopoulou G, Karagouni E, Dotsika E. ISCOMs vaccine against experimental leishmaniasis. Vaccine. 1998;16(9-10):885-892.

34. Myschik J, Lendemans DG, McBurney WT, Demana PH, Hook S, Rades T. On the preparation, microscopic investigation and application of ISCOMs. Micron. 2006;37(8):724-734.

35. Ruiz-Perez LM, Osuna A, Lopez MC, et al. Activity of rhodium(III) complexes against Trypanosoma cruzi. Arzneimittelforschung. 1988; 38(2):312-314.

36. Bradford MM. A rapid and sensitive method for the quantitation of microgram quantities of protein utilizing the principle of protein-dye binding. Anal Biochem. 1976;72:248-254.

37. De Pablos LM, González GG, Solano Parada J, et al. Differential Expression and Characterization of a Member of the Mucin-Associated Surface Protein Family Secreted by Trypanosomacruzi. Infect Immun. 2011;79(10):3993-4001.

38. Coe JE, Coe PR, Ross MJ. Staphylococcal protein A purification of rodent IgG1 and IgG2 with particular emphasis on syrian hamsters. Mol Immunol. 1981;18(11):1007-1012.

39. Graille M, Stura EA, Corper AL, et al. Crystal structure of a Staphylococcusaureus protein A domain complexed with the Fab fragment of a human IgM antibody: Structural basis for recognition of B-cell receptors and superantigen activity. Proc Natl Acad Sci U S A. 2000;97(10):5399-5404.

40. Shpigel E, Goldlust A, Eshel A, et al. Expression, purification and applications of staphylococcal protein A fused to cellulose-binding domain. Biotechnol Appl Biochem. 2000;31( Pt 3):197-203.

41. Guss B, Uhlén M, Nilsson B, Lindberg M, Sjöquist J, Sjödahl J. Region X, the cell-wall-attachment part of staphylococcal protein A. Eur J Biochem. 1984;138(2):413-420.

42. Uhlén M, Guss B, Nilsson B, Gatenbeck S, Philipson L, Lindberg M. Complete sequence of the staphylococcal gene encoding protein A. A gene evolved through multiple duplications. J Biol Chem. 1984;259(3): 1695-1702.

43. Harbers E, Mueller W. On the inhibition of RNA synthesis by actinomycin. Biochem Biophys Res Commun. 1962;7:107-110. 
44. Waksman SA, Geiger WB, Reynolds DM. Strain Specificity and Production of Antibiotic Substances: VII. Production of Actinomycin by Different Actinomycetes. Proc Natl Acad Sci U S A. 1946;32(5): 117-120.

45. Fernandes JF, Halsman M, Castellani O. Effect of actinomycin D on the infectivity of Trypanosoma cruzi. Nature. 1965;207(5000): 1004-1005.

46. Gentil LG, Cordero EM, do Carmo MS, dos Santos MR, da Silveira JF. Posttranscriptional mechanisms involved in the control of expression of the stage-specific GP82 surface glycoprotein in Trypanosoma cruzi. Acta Trop. 2009;109(2):152-158.
47. Kerr ID, Lee JH, Farady CJ, et al. Vinyl sulfones as antiparasitic agents and a structural basis for drug design. J Biol Chem. 2009;284(38): 25697-25703.

48. Storm G, Belliot SO, Daemen T, Lasic DD. Surface modification of nanoparticles to oppose uptake by the mononuclear phagocyte system. Adv Drug Deliv Rev. 1995;17(1):31-48. 


\section{Supplementary materials}

The ${ }^{1} \mathrm{H}$ NMR and ${ }^{13} \mathrm{C}$ NMR were analyzed in a $300 \mathrm{MHz}$

Varian Inova Unity with a broadband $\left({ }^{13} \mathrm{C}\right.$ and $\left.{ }^{1} \mathrm{H}\right)$ probe.

$$
\begin{aligned}
& \text { AL } 147 \\
& \text { Archive directory: } \\
& \text { Sample directory: } \\
& \text { File: PROTON }
\end{aligned}
$$

File: PROTON

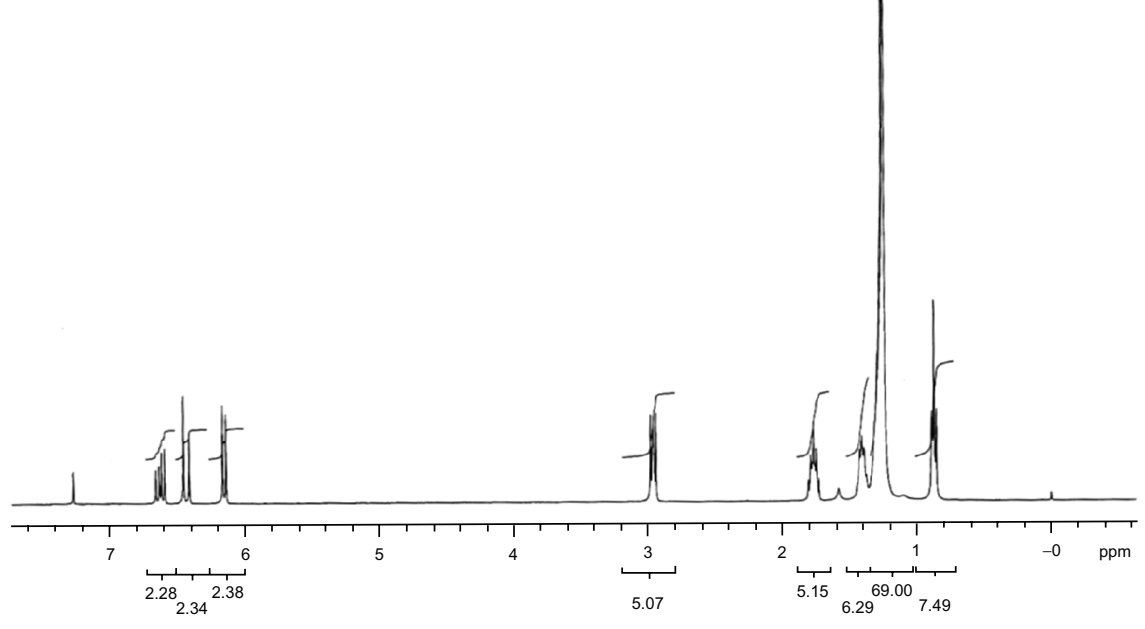

Figure SI 'H NMR spectra for compound 4.
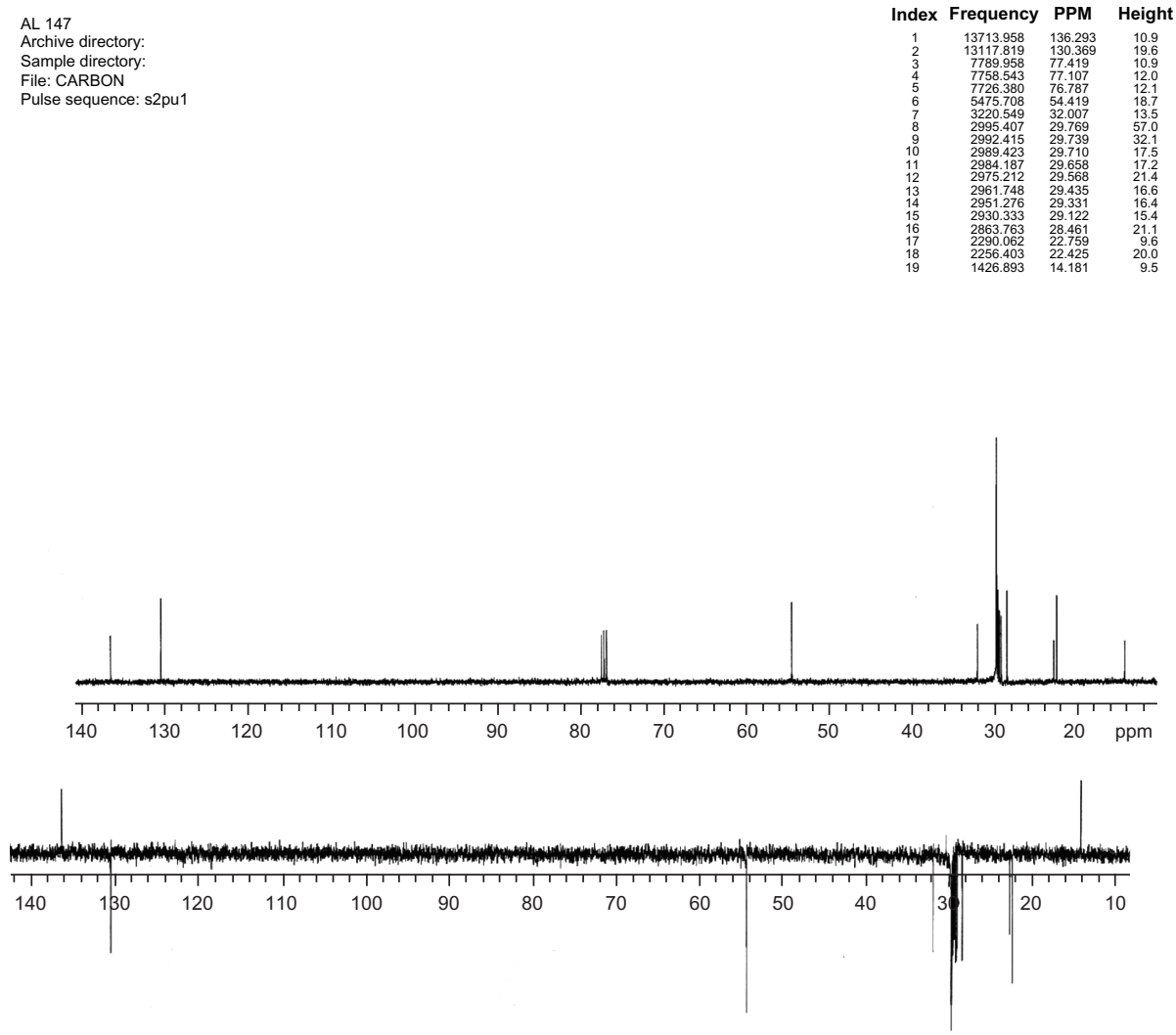

Figure S2 ${ }^{13} \mathrm{C}$ and DEPT NMR spectra for compound 4. 


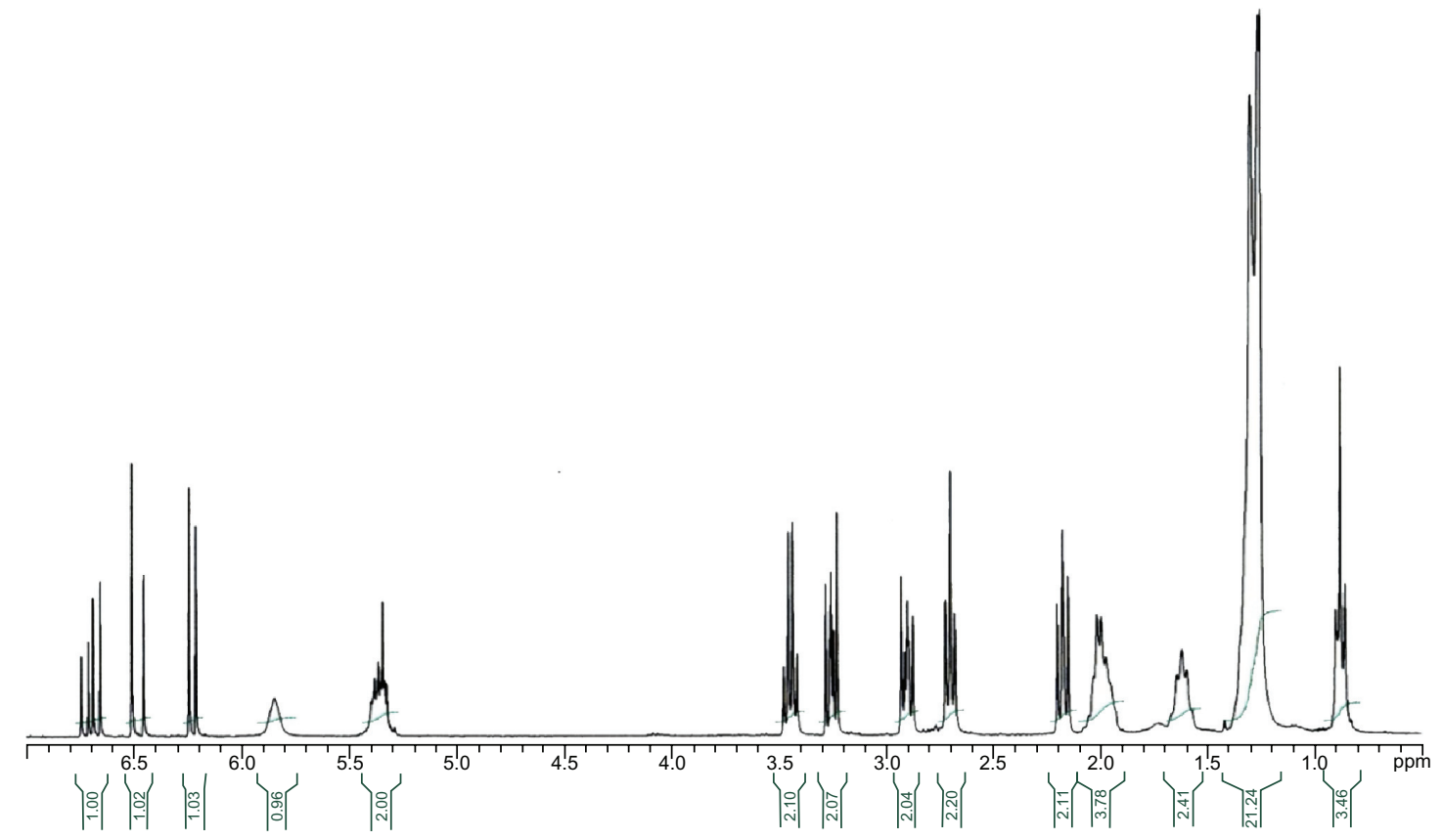

Figure S3 'H NMR spectra for compound 7.
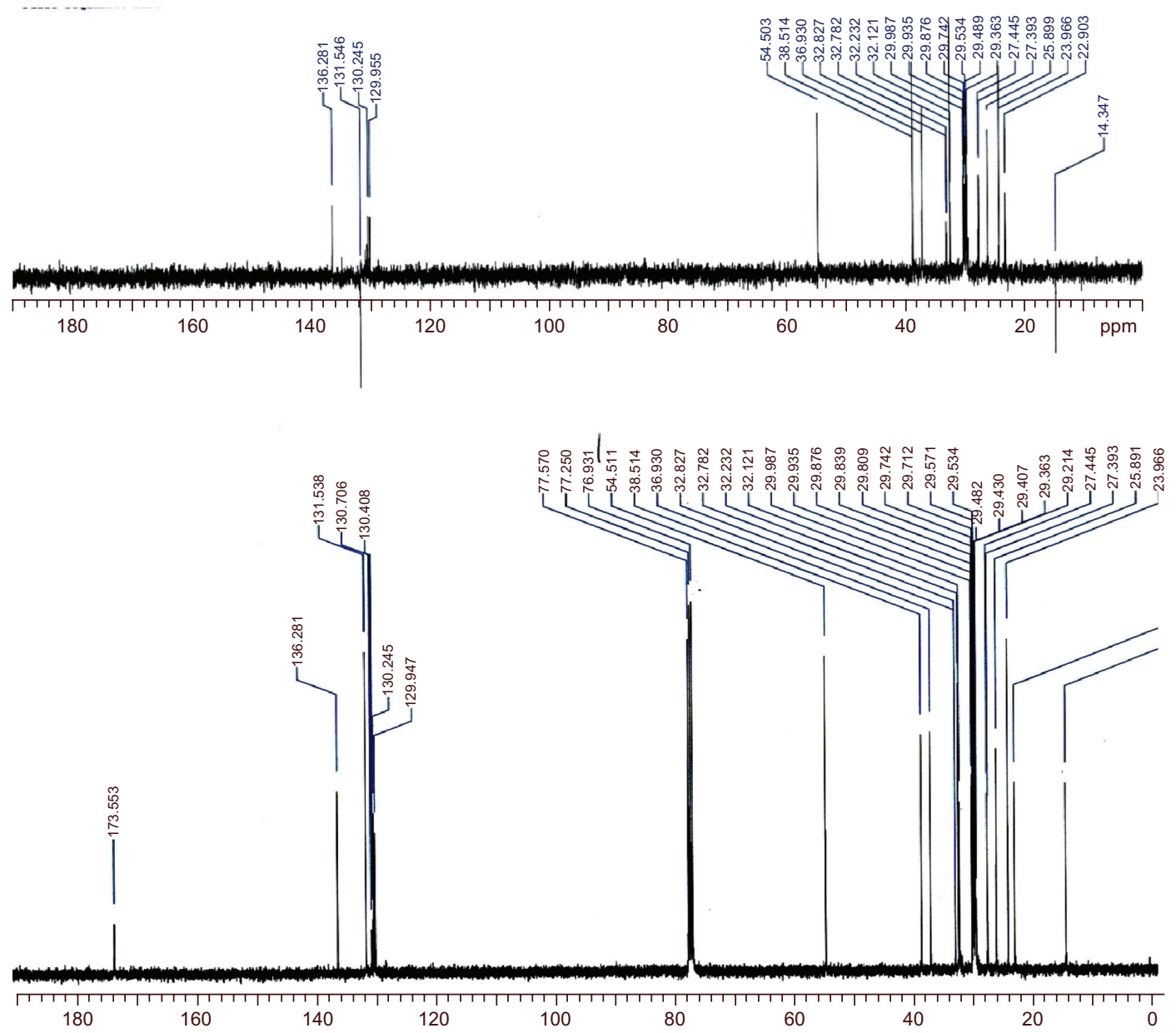

Figure S4 ${ }^{13} \mathrm{C}$ and DEPT NMR spectra for compound 7. 


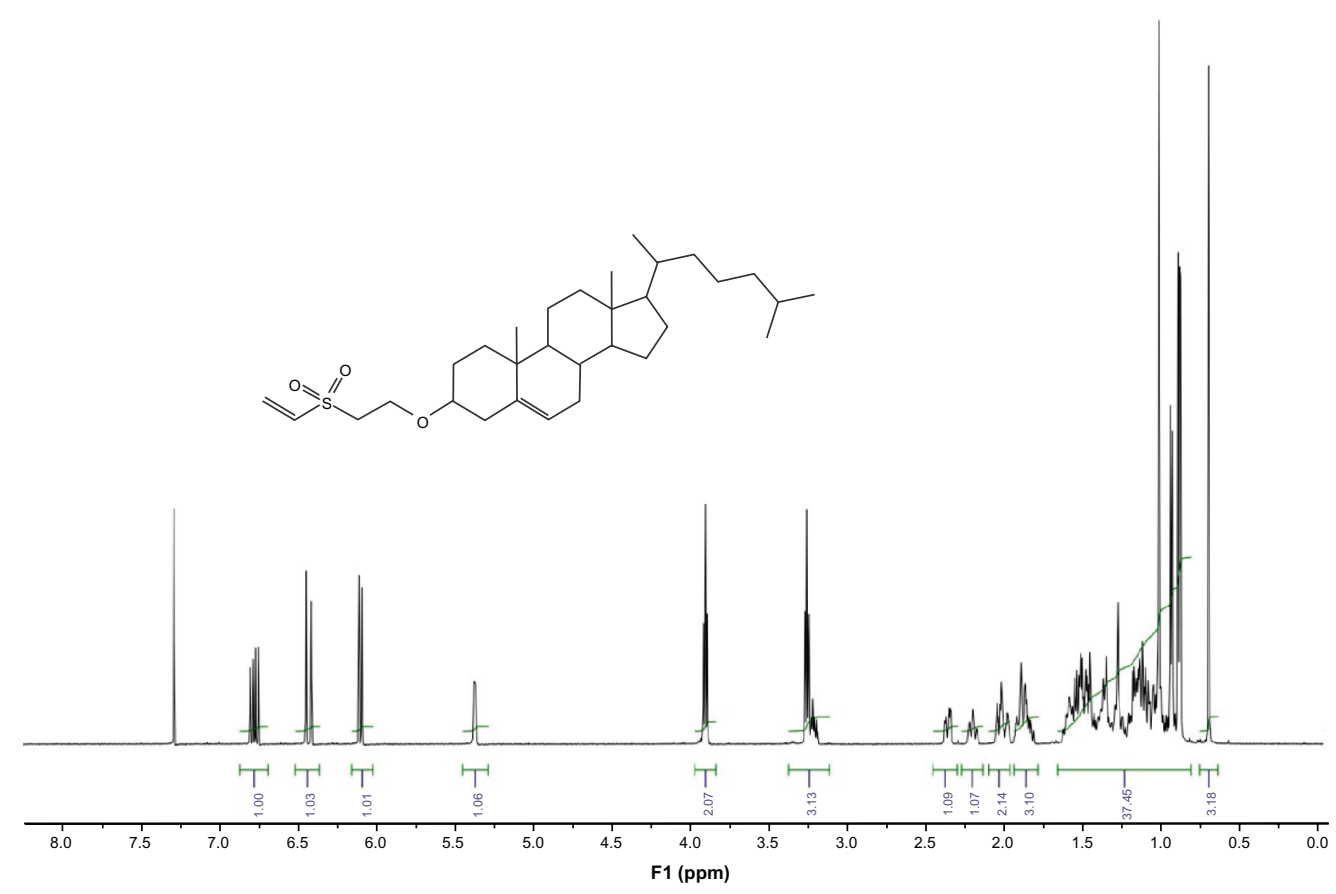

Figure S5 'H NMR spectra for compound 9.
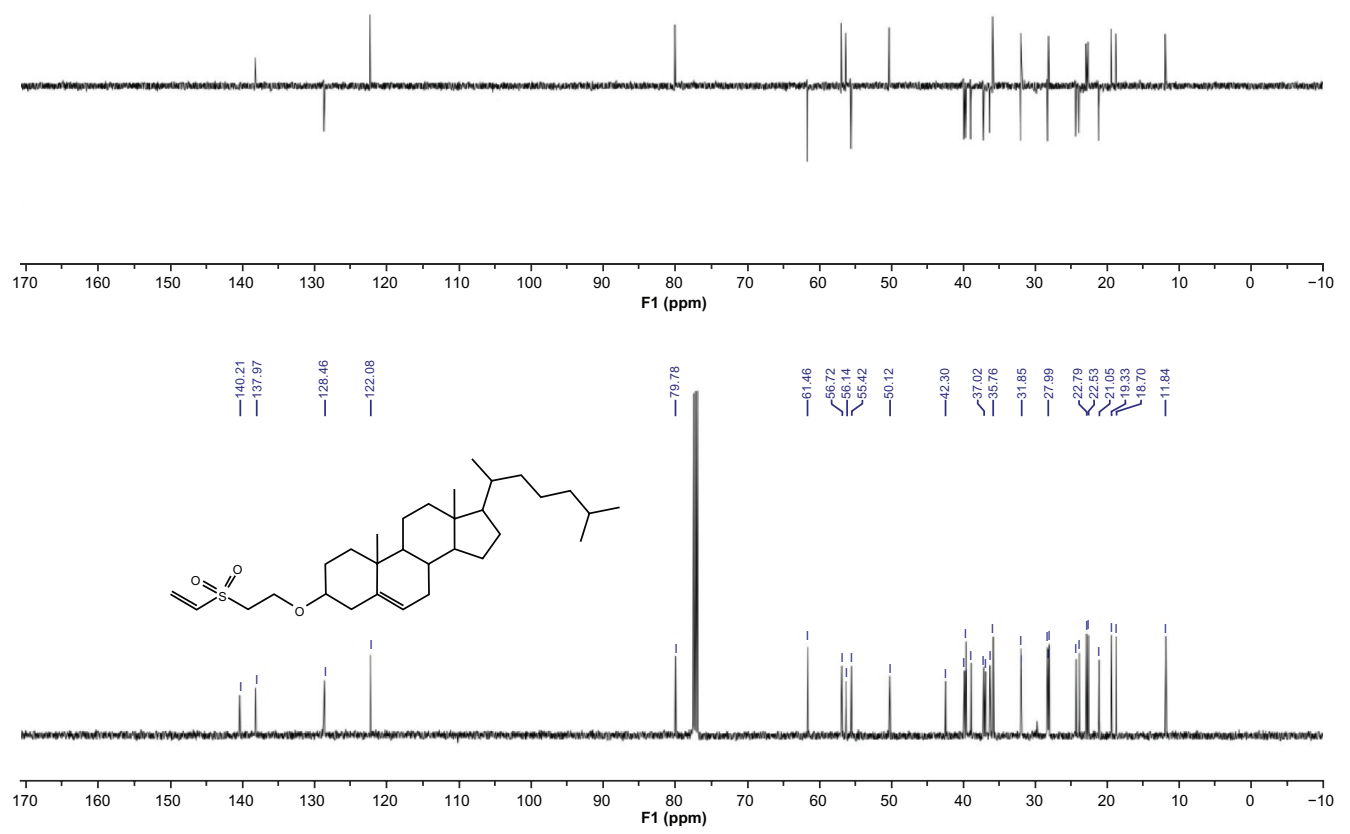

Figure $\mathbf{S 6}{ }^{13} \mathrm{C}$ and DEPT NMR spectra for compound 9.

International Journal of Nanomedicine

Dovepress

\section{Publish your work in this journal}

The International Journal of Nanomedicine is an international, peerreviewed journal focusing on the application of nanotechnology in diagnostics, therapeutics, and drug delivery systems throughout the biomedical field. This journal is indexed on PubMed Central, MedLine, CAS, SciSearch ${ }^{\circledR}$, Current Contents ${ }^{\circledR} /$ Clinical Medicine,

Journal Citation Reports/Science Edition, EMBase, Scopus and the Elsevier Bibliographic databases. The manuscript management system is completely online and includes a very quick and fair peer-review system, which is all easy to use. Visit http://www.dovepress.com/ testimonials.php to read real quotes from published authors.

Submit your manuscript here: http://www.dovepress.com/international-journal-of-nanomedicine-journal 